\title{
O ENSINO DE TEATRO PARA IDOSAS NA PERIFERIA DE SANTA MARIA/RS
}

\section{THEATER TEACHING FOR ELDERLY PEOPLE ON THE OUTSIDE OF SANTA MARIA / RS}

\section{DOI: http://dx.doi.org/10.5965/1984317816012020295}

\author{
Laís Jacques Marques \\ Universidade do Estado de Santa Catarina \\ laisjmarques@hotmail.com
}

\begin{abstract}
RESUMO
Este estudo tem por objetivo relatar a prática de Teatro com idosas em uma comunidade da periferia de Santa Maria - RS. Com estas mulheres buscou-se promover um distanciamento crítico da realidade (vivenciada por elas), facilitada pela realização de uma oficina teatral, baseada na prática do Teatro e da pedagogia do oprimido freireano. O processo de escrita e reflexão sobre a trajetória da oficina, utilizou-se de cartografias (transduzindo a realidade e a prática teatral, em uma via dupla), conversas, leituras e discussões de textos com o grupo. Estes percursos nos levaram a operações significativas sobre o cotidiano das mulheres envolvidas, como mudanças nos hábitos corporais, na qualidade das relações humanas e, principalmente, na percepção da realidade que permeia a rotina de trabalho e lazer das idosas.
\end{abstract}

Palavras-chave: Ensino de teatro para idosas; Prática do oprimido; Teatro com a comunidade.

\begin{abstract}
This study aims to report the practice of theater with elderly women in a community on the outskirts of Santa Maria - RS. With these women we sought to promote a critical distance from reality (experienced by them), facilitated by the realization of a theatrical workshop, based on the practice of the theater and the pedagogy of the oppressed Freirean. The process of writing and reflection on the workshop's trajectory, used cartographies (transducing reality and theatrical practice, in a double way), conversations, readings and discussions of texts with the group. These paths led us to significant operations on the daily lives of the women involved, such as changes in body habits, the quality of human relationships and, especially, the perception of the reality that permeates the work and leisure routine of the elderly.
\end{abstract}

Keywords:Theater teaching for the elderly; Practice of the oppressed; Theater with the community.

\section{PRINCÍPIO DO QUEFAZER ARTíSTICO}

A pesquisa - O ensino de Teatro para mulheres idosas na periferia de Santa Maria - teve por objeto de estudo as práticas sociopedagógicas necessárias para gerir, desenvolver e consolidar um grupo de Teatro com mulheres de maior idade. ${ }^{1}$ Como mote da pesquisa, escolhi agenciar práticas pedagógicas de Teatro, da

1 Por este termo, compreendemos pessoas com idade igual ou superior a 60 anos ( Lei no 10.741 , de $1^{\circ}$ de outubro de 2003). 
Educação e suas diversas possibilidades de atuação em entrelace à realidade em que me encontro.

As aulas de Teatro iniciadas em abril de 2018 se deram na Associação Esperança, espaço cedido pela prefeitura para atividades voluntárias. Sem utilização a mais de cinco anos, a associação é situada na Rua Fernando Mello, n¹05, Cohab Fernando Ferarri, bairro Camobi. O bairro foi escolhido por sua proximidade com a Universidade Federal de Santa Maria (UFSM) e por possuir pouca ou nenhuma produção artística e cultural. Identificamos, em conversas e em relatos de mulheres moradoras da comunidade a necessidade (e mais do que isso, o desejo) de interação da melhor idade com o entorno sociocultural da cidade.

A partir disso, passamos - as mulheres moradoras do bairro, e eu - a nos encontrar duas noites por semana para realizar exercícios e jogos teatrais com o enfoque inicial em realizar alongamentos. Entre estes caminhos, percebendo o interesse das participantes, adentrei no trabalho sobre a percepção de vícios de movimento (mecanicidade corporal) que restringia a movimentação cotidiana e extracotidiana das mulheres. A prática de conscientizar-se dos próprio vícios de movimento foi tomando concretude a partir das teorias de Augusto Boal ${ }^{2}$ e realizadas de maneira gradual, sendo prioridade o conforto e completo entendimento do grupo das propostas que executavam. $O$ intuito foi que caminhássemos no sentido contrário ao da "alienação muscular", teorizada por Boal (1997) enquanto modulações corporais consequentes das profissões exercidas durante a vida. Nossos encontros finalizavam-se com a leitura e reflexão de textos da estadunidense Clarissa Estés (1945) selecionados com o intuito de fortalecer e, em alguns casos, reestruturar a autoestima das mulheres.

As participantes, em sua maioria, eram mulheres trabalhadoras, com baixa escolaridade - a maioria delas possuía ensino fundamental incompleto - e inconscientes de seus direitos sociais como, por exemplo o acesso a cultura. Ao considerar tais condições, objetivei, com a oficina, promover inicialmente o retorno da experiência teatral acumulada por mim na graduação àquelas que não possuíram o mesmo privilégio, bem como proporcionar visibilidade para a comunidade. Mais

2 (1931 - 2009) Teatrólogo brasileiro, fundador do Teatro do Oprimido, pedagogia teatral que alia a linguagem da cena a ações sociais. 
motivos me fizeram notar as senhoras como potência criativa: a falta de local de fala para idosos e o próprio desconhecimento de suas histórias e trajetórias, o que torna a relação entre idosos-jovens, a cada dia, mais distante e com maior necessidade de incentivo. Sendo assim, a estruturação de um grupo teatral conjecturou promover ações culturais para o bairro, além de criar alteração na rotina das senhoras e proporcionar-Ihes momentos de descontração. Desta forma, com o passar do tempo de execução das práticas, dei-me por conta que o enrijecimento não residia somente nos corpos das mulheres, mas em seus valores e posicionamentos políticos. Estes aguardavam, também, por uma revisão e atualização lúcidas de seu tempo.

A seguir, apresento debates referentes ao valor histórico e o visível descaso com o idoso, bem como métodos de trabalho aderidos no desenvolvimento do processo. Utilizo, para tais temas, os entendimentos esboçados por Ecléa Bosi, ${ }^{3} \mathrm{e}$, para suscitar hipóteses de possíveis resoluções em danos na autoestima da mulher, Clarissa Estés ${ }^{4}$. Ambas apontarão a urgência da preocupação com a mulher velha. Aponto que podemos ler os destaques de ambas através das teorizações conscientes de Paulo Freire ${ }^{5}$ e de Augusto Boal.

Em Paulo Freire (1987) encontro a ideia de quefazer artístico, centro de minha proposta poética teatral para com as mulheres idosas. Tal ideia-conceito freireano trata da realização de um diagnóstico das deficiências socio-culturais e a elaboração de ferramentas (práticas) capazes de sanar as necessidades da realidade em questão. Baseada nos relatos do grupo de mulheres idosas com o qual convivi - corporal e poéticamente -, observei que muitas delas tinham interesses e curiosidades em ter contato com a universidade (sitiada aos arredores do bairro no qual residiam) e em mobilizar um novo sopro de vida - teatral, cultural, social - para si e para o bairro no qual residiam.

3 (1936 - 2017) Dr em psicologia social pela Universidade de São Paulo (1971), professora e pesquisadora.

4 (1945) Psicanalista analítica norte americana. Utilizada para elucidar reestruturações nos arquétipos femininos em prol da saúde mental da mulher.

5 (1921 - 1997) Educador, pedagogo, filósofo e Patrono da educação brasileira. Suas influências para a construção de uma pedagogia crítica serão o enfoque da pesquisa. 


\section{MÉTODOS DE APLICABILIDADE E PARES TEÓRICOS}

A simultaneidade da pesquisa, considerando o período de sua efetivação ser concomitante ao de elaboração da oficina me fez acessar a metodologia cartográfica. Para a brasileira Rolnik (1989), cartografar é adentrar na história do objeto, possibilitando moldá-lo e torná-lo sensível. A pesquisadora no diz que "[...] não há distinção entre o que há em cima e embaixo da esfera cartográfica, mas por cima, por baixo, pelo meio e por todos os lados, só há intensidade buscando expressão" (ROLNIK, 1989, p. 4). A partir disso, compreendo que cartografar é conhecer e criar elos em esferas amplas e profundas com o objeto estudado.

A partir disto, há a etapa do reconhecimento do sujeito, objeto de estudo: inserimo-nos no local - Associação Esperança - no período de doação de alimentos excedentes do Restaurante Universitário aos moradores em situação de vulnerabilidade social do bairro. Expliquei meu interesse e minha procura por espaços de práticas teatrais com elas, e as convidei para participarem. Desde então, ampliou-se a participação de mulheres semanalmente. Por este motivo, desenvolvi a pesquisa a partir das etapas do Teatro do Oprimido de Augusto Boal, para sistematizar o processo teatral e culminar as experiências em apresentações de Teatro Fórum.

A divulgação da oficina teatral, para além do convite pessoal, também se deu através de cartazes espalhados pelo bairro. A arte foi elaborada pelo artista Jorge Gularte (também morador do bairro), que utilizou como referência xilogravuras de cordéis nordestinos e de cirandas de mulheres de culturas aborígenes.

O nome do grupo foi escolhido através de conversas e de leituras do livro de Clarissa Estés (2011), Ciranda das Mulheres Sábias, em que a autora une mitologias e lendas entre faixa etárias e culturas de distintas mulheres. As contadoras de histórias (personagens do livro) se unem por compreender que juntas podem trocar experiências ricas e melhorar a saúde física e psicológica de muitas mulheres que se encontram em situações depressivas, ansiosas ou demais fragilidades emocionais. 


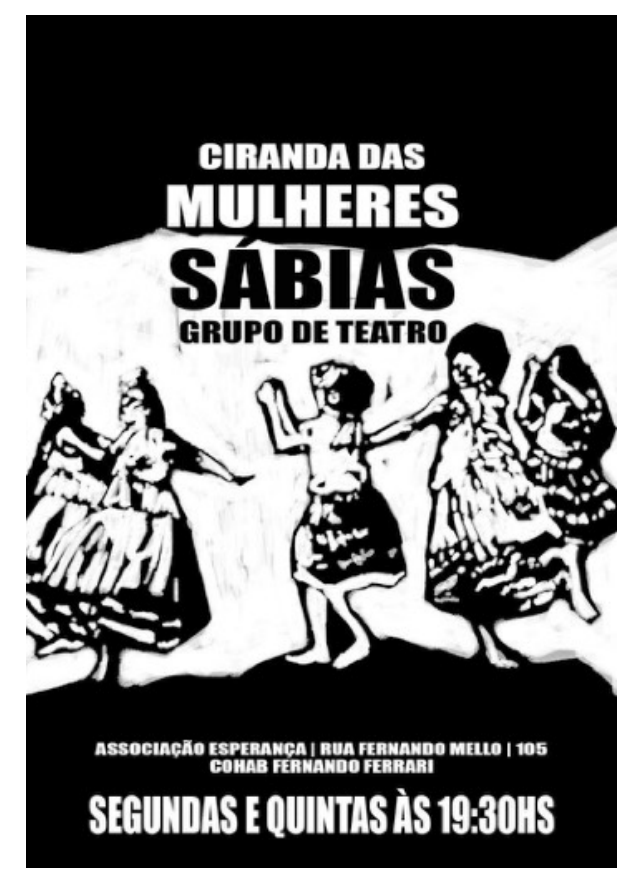

Figura 1 - Arte de divulgação, por Jorge Gularte. Abril de 2018.

\section{AUGUSTO BOAL E O TEATRO DO OPRIMIDO: TODO MUNDO PODE FAZER TEATRO!}

Nossos encontros compreenderam, em termos práticos, os processos laboratoriais de jogos e exercícios, inicialmente propostos com o intuito de trabalhar a "desalienação corporal" (BOAL, 1977, p. 107). Boal sublinha sua relevância ao dizer que necessitamos reconhecer nossas limitações físicas, capacidades de mudança e adaptações para que se torne possível a comunicação através da linguagem teatral (1977). Com o corpo amenizado da mecanicidade cotidiana, mesmo que no nosso segundo mês de trabalho, pude notar, o diálogo entre as senhoras se fez mais expressivo.

O método teatral desenvolvido por ele tem como estímulo questionar a realidade através do diálogo, e visa, com o diálogo não somente verbal, mas corporal, modificá-la. Intitulado como Teatro do Oprimido, é dividido em cinco grandes eixos. São eles:

- Teatro Jornal, que, com o jornal do dia, os participantes devem representar alguma notícia e estimular o público a intervir no final da matéria. Geralmente 
apresentado em sindicatos, comunidades, escolas ou universidades, possui caráter principalmente informativo.

- O Teatro Invisível se refere a cenas ou espetáculos de curta duração que ocorrem em locais inusitados (bar, restaurante, ônibus, fila do mercado, etc).

público não é avisado da realização da peça, e por vezes há embates travados contra o elenco. Geralmente as peças criticam relações de machismo, racismo, disparidade de classe social, entre outros.

- No Teatro Imagem os participantes montam "estátuas" com palavras/temas específicos. As colegas integrantes do grupo devem compor junto as companheiros uma estrutura maior e mais elaborada com seus próprios corpos, sempre relacionado aos temas propostos pela condutora do exercício.

- No Teatro Legislativo, os participantes explanam leis a serem votadas no congresso, substituindo os votantes que, ao invés de parlamentares, são o público.

- Por fim, no Teatro Fórum, os atores representam o espetáculo até o momento de conflito, quando a figura do narrador interrompe a cena para perguntar ao público quais os finais Ihes agradaria mais. Foram em sessões de Teatro Fórum que integrantes da plateia se sentiram livres para entrar em cena também, e criar assim o que Boal teoriza enquanto espect-atores. ${ }^{6}$

\section{CRUZAMENTOS DOS PARES BIBLIOGRÁFICOS}

Em reflexões dadas a partir da compreensão da relevância do trabalho tanto do Teatro quanto da pedagogia do oprimido, encontra-se em Bossi (1994) o entendimento de que "se trata de uma pedagogia que possa dar conta de uma situação precisa, no universo das relações sociais, de uma certa camada da população subjugada pela dependência. Opressão: dependência (BOSI,1994, p. 21)." Talvez pela rotina acelerada, estejamos a cada dia com menos tempo e paciência para a lida e troca de experiências com pessoas de maior idade. Os

6 DESGRANGES, F. (2006) "Uma cena é apresentada pelos atores que buscam um fato significativo, uma situação de opressão comum àquela comunidade específica. Quando a encenação termina, pergunta-se ao espectador se estão de acordo com a solução encontrada. [...] A cena é então reapresentada e é então proposto aos participantes que interrompam a reapresentação no momento que lhes parecer conveniente, para que substituam os atores, agora espect-atores."(DESGRANGES, 2006, p. 72) 
valores foram substituídos pela pressa, nossa relação com o outro tem se tornado diariamente distante. Neste momento de aceleração, julgo importante reconhecer os valores que nos foram legados, e nas palavras de Bosi, "entender as relações entre a conservação do passado e a sua articulação com o presente (BOSI, 1994, p.47)." De encontro a ela, Freire diz:

[...] percebo afinal que a construção de minha presença no mundo, que não se faz no isolamento, isenta da influência das forças sociais, que não se compreende fora da tensão entre o que herdo geneticamente e o que herdo social, cultural e historicamente. (FREIRE, 2016, p.53).

Acredito sermos formados pelo meio, pela cultura nos engendrada e principalmente pelos diálogos que consolidamos. Viabilizamos, entre as senhoras, os discursos horizontais, para que a fala se dê de maneira conjunta, pois, como bem coloca Freire (1987) "a educação autêntica não se faz de A para B ou de A sobre B, mas de A com B, mediatizados pelo mundo (FREIRE, 1987, p. 84)." Penso ter servido de ponte, de fomento ao diálogo entre estes universos, em contato direto com jogos de Teatro no intuito de promover a visualização de outras perspectivas da realidade problematizada.

Reitero que a relação dialógica justifica-se na escolha contrária ás metodologias opressoras, para unificar histórias e emergir, florescer do corpo à mente das mulheres, ações libertas, alegres, pois "neste momento primeiro da ação, como síntese cultural, que é a investigação, se vai constituindo o clima da criatividade, que já não se deterá (BOAL, 1982, p. 134)."

Essas evoluções pressupõem um olhar atento para trás, movimento o qual por vezes a sociedade não nos dá tempo de realizar, enquanto paradoxalmente, nos exige autonomia. Quando articulamos pensamentos subjetivos, a visualização de ângulos diferentes torna-se primordial. Assim como coloca Boal ao falar sobre espect-ator: "como somos todos espect-atores, descobrindo o teatro, o ser se descobre humano. O teatro é isso: a arte de nos vermos a nós mesmos! A arte de nos vermos vendo! (BOAL, 1977, p. 127)." 
As experiências com espec-atores permitem trocas desenvolvidas por sujeitos que não necessariamente tenham contato com a representação, sendo de importância maior a participação ativa dos participantes e não mais coadjuvantes de suas histórias. Portanto, ouvir as idosas, suas reivindicações e memórias, torná-las potências artísticas e posteriormente públicas, foi o que pretendeu o trabalho.

O intuito nesta etapa foi o de realizar um compartilhamento com a comunidade no formato do Teatro Fórum, que, apresentado em locais de grande circulação, possui o objetivo de instigar o público a participar das apresentações. Ao levantar questionamentos em que o público deve atuar na situação do personagem, o espectador é convidado a executar o fim que deseja á cena. O público é, portanto, agente fundamental na apresentação. Segundo Boal (1998), "o teatro deve modificar o espectador, dando-lhe consciência do mundo em que vive e do movimento desse mundo. O teatro dá ao espectador a consciência dessa realidade; é ao espectador que cabe modificá-la (BOAL, 1998, p. 26)." Posso dizer então, que as participantes idosas proponentes das ações encontraram no Teatro veículo de comunicação social.

O que faz com o que os dois mestres (Augusto Boal e Paulo Freire) estejam abraçados na perspectiva de auxiliar na qualidade de vida da terceira idade são justamente seus empenhos ferrenhos por uma pedagogia de liberdade e autonomia. Acreditamos que os praticantes de suas técnicas adquiriram ferramentas para abandonar o lugar autômato e passaram a enxergar na realidade espaço de modificação. Como coloca Boal "O teatro é uma arma, e é o povo quem deve manejá-la! (BOAL, 1977, p.127)." Difundir suas potencialidades com a comunidade é de certa forma um ato político.

Bosi agrega embasamento político fortalecido por entrevistas com aposentados metalúrgicos da indústria de São Paulo. Sobre o valor social do idoso, nos diz:

A sociedade rejeita o velho, não oferece sobrevivência à sua obra. Perdendo a força de trabalho ele já não é produtor nem reprodutor. Se a posse, a propriedade, constituem, segundo Sartre, uma defesa contra o outro, o velho de uma classe favorecida defende-se pela acumulação de bens. Suas propriedades o defendem da desvalorização de sua pessoa. O velho não participa da produção, 
não faz nada: deve ser tutelado como um menor. (BOSSI, 1994, 77p.)

É o caráter de protagonista que desejo lhes devolver, e, assim como segue Bosi, "sua vida ganha uma finalidade se encontrar ouvidos atentos, ressonância [...] [/] pois [...] um mundo social que possui uma riqueza e uma diversidade que não conhecemos chegar-nos pela memória dos velhos (BOSI, 1994, p.82)." Assim, considero que a coletividade proposta pelo Teatro é capaz de manifestar, nos indivíduos, expressão individual e, em conjunto, agenciar a potencialidade de cura das atividades culturais.

Por cultura, Estés alerta para seu caráter disseminador não só de signos benéficos, mas manifestante de traumas no seio coletivo por vezes não explanados:

Embora uma grande vertente da psicologia dê ênfase a causas familiares na angústia dos seres humanos, o componente cultural tem o mesmo peso, pois a cultura é a família da família. Se a família da família sofre de várias enfermidades, todas as famílias dentro daquela cultura terão de lutar com os mesmos, inconscientes (ESTÉS, 2014, p.85).

A cultura na qual me circunscrevi carecia de uma visão lúcida, consciente e crítica alcançada pela prática teatral realizada com o grupo de mulheres idosas. A prática do jogo entrelaçada a ações cotidianas ambicionou o resgate do lugar potente criador das participantes, bem como prezou explorar movimentos conhecidos do cotidiano. Refazer atividades, estimuladas por sugestões que partiram de situações corriqueiras é um artefato de improvisações ${ }^{7}$ que busca o olhar para si com atenção redobrada e distanciada.

Momentos de compartilhamento de recordações e de memórias (sejam elas pessoais ou coletivas, como a história do bairro e da cidade) também fizeram parte dos encontros, primeiramente para estimular uma espécie de auto-encontro e de

\footnotetext{
7 SPOLIN, V. Improvisações para o teatro. Nos jogos teatrais propostos pela pedagoga, as circunstâncias são modificadas por instrução do condutor da prática, incluindo sentimentos e sensações em cada tarefa do cotidiano: como me banho com sono? Como é o banho para um encontro amoroso? Como banho uma criança? Como reajo quando batem na porta do banheiro? Etc. (SPOLIN, 2010, p. 139)
} 
exigir atenção interior e imaginação; a posteriori, para criar suposições e história. O objetivo foi enfatizar a sensibilidade das mulheres:

Creio que todos os homens e mulheres nasceram com talentos. No entanto, a verdade é que houve pouca descrição dos hábitos e das vidas psicológicas de mulheres talentosas, criativas, brilhantes. Muito foi escrito, porém, a respeito das fraquezas e defeitos dos seres humanos em geral e das mulheres em particular (ESTÉS, 2014, p. 23).

Reestruturar a feminilidade através da criação é o que sugere Estés (2014). Segundo ela, as mulheres possuem naturalmente o caráter criador aguçado. Colocálo em movimento enaltece possíveis aptidões por vezes abandonadas (ESTÉS, 2014). As sugestões para estimular o estado criativo são diversas, no entanto, o contato com culturas similares e meios sociais de condições semelhantes são os métodos mais eficazes comprovados pela antropóloga para atingir o desbloqueio artístico.

\section{PENSAMENTOS FINAIS}

É possível afirmar então que o acesso a produções artísticas em ambiente não estatal ou institucional necessitam de estímulo. Por prezar pelo convívio e pela inserção intensa no local em que vivo, optei por dialogar com as participantes sobre nossas visões do mundo, sem nenhuma espécie de imposição. Foi assim que recorri ao Teatro e a Pedagogia do Oprimido (BOAL, 1977, FREIRE, 1987). Ao aprofundar conhecimentos pedagógicos freireanos, além da historiografia da região, adquiri também base para efetivar o processo prático de Teatro, bem como os exercícios e jogos conceituados por Boal. Nele, a oralidade e os debates horizontais do grupo foram questões fundamentais, por isso a aproximação de sua realidade e do pensamento de Freire.

Ao considerar tais proposições, almejei promover inicialmente o retorno da experiência que adquiri na graduação àquelas que não possuíram o mesmo privilégio. Como resultado, percebi que a prática teatral operou mudanças nos hábitos corporais, na qualidade das relações humanas, nos hábitos de saúde e higiene mental, no distanciamento crítico em relação a realidade que permeia rotinas 
de trabalho e de lazer das mulheres participantes. Uma Sra. com aproximadamente 70 anos, que em nosso primeiro encontro (06 de abril do ano de 2018) necessitou de auxílio para levantar do chão de onde se deitara, já conseguia se erguer sozinha, além de todas relatarem maior disposição para atividades domésticas e melhor desempenho em memorizações. Isto em menos de dois meses de atividades práticas.

No ano de 2019 fui convidada por um coletivo feminista organizado através do MOICA (Movimento de Insurgência Camponesa), pequenas agricultoras da cidade de Santo Ângelo, á dividir minhas experiências teatrais. As doze senhoras (mulheres entre trinta e oitenta e seis anos) se reuniram na Associação de Moradores do bairro situado em Catuçaba - Santo Ângelo - RS, em um domingo em que os termômetros marcavam precisamente $0^{\circ} \mathrm{C}$. Fui recebida com carinho e expectativa, e, ainda nos exercícios de alongamento, percebi o quão importante para elas era o fato de estarem juntas. Muito mais do que exercícios teatrais, realizamos trocas de saberes, de angústias, medos e esperanças campesinas. A reverberação deste trabalho realizado evidencia, em meu entendimento, que todas as pessoas podem (e deveriam) fazer Teatro, e que a arte é sem dúvida capaz de unir diversos universos.

\section{REFERÊNCIAS}

BRASIL, Leis de Diretrizes e Bases da Educação Nacional n9394/96. Brasília, 1996. Ministério da Educação. Proposta Curricular. Educação Para Jovens e Adultos. São Paulo/Brasília: 2001.

Presidência da República, Casa Civil. Estatuto do Idoso. LEI № 10.741 , de $1^{\circ}$ de outubro de 2003. Brasília: 2007. Disponível em: http://www.planalto.gov.br/ccivil_03/leis/ 2003/L10.741compilado.htm

BOAL, Augusto. Teatro do Oprimido e outras poéticas políticas. $2^{\mathrm{a}}$ Ed. Rio de Janeiro: Civilização Brasileira, 1977.

200 Exercícios e jogos para o ator e o não-ator com vontade de dizer algo através do teatro. $4^{a}$ ed. Rio de Janeiro: Civilização Brasileira S.A., 1982;

S.A., 2014;

Jogos para atores e não atores. 16 ed. Rio de Janeiro: Civilização Brasileira

BOSI, Ecléa. Memória e sociedade. Lembrança dos velhos. $3^{\mathrm{a}}$ ed. São Paulo: Companhia das Letras, 1994. 
2003.

O tempo vivo da memória.Ensaios de psicologia social. $2^{a}$ ed. Ateliê Editorial,

DESGRANGES, Flávio. Pedagogia do Teatro. Provocações e dialogismo. São Paulo:

Editora Hucitec, 2006.

ESTÉS, P. Clarissa. A ciranda das mulheres sábias. Rio de Janeiro. Rio de Janeiro, Rocco, 2011;

Mulheres que correm com os lobos. Mitos e histórias do arquétipo da Mulher Selvagem. Rio de Janeiro, Rocco, 2014;

FREIRE, Paulo. Pedagogia do oprimido. São Paulo, $17^{\text {a }}$ Ed. Paz e Terra, 1987;

Pedagogia da autonomia: saberes necessários a prática educativa. São Paulo, 54 ${ }^{\text {a }}$ Ed. Paz e Terra, 2016.

ROALYNM Suely. Cartografia ou de como pensar com o corpo vibrátil. Revista PUC SP. Disponível em: http://www.pucsp.br/nucleodesubjetividade/Textos/SUELY/pensarvibratil.pdf Cartografia Sentimental, Transformações contemporâneas do desejo, Editora Estação Liberdade, São Paulo, 1989.

SPOLIN, Viola. Improvisação para o teatro. São Paulo: Perspectiva, 2010. 